S. Goolak, Ie. Riabov, V. Tkachenko, S. Sapronova, I. Rubanik

\title{
Model of pulsating current traction motor taking into consideration magnetic losses in steel
}

The aim of the work is to develop a mathematical model of the traction motor of the pulsating current of an electric locomotive taking into account the magnetic losses in the motor steel to determine the starting parameters depending on the voltage of the armature winding. Methodology. Mathematical modeling of electromagnetic processes in a traction motor of pulsating current is applied taking into account the nonlinear nature of the armature inductance, the inductance of the excitation winding and the nonlinear nature of the universal magnetic characteristic. The magnetic losses in the steel of the traction motor were taken into account by establishing the dependence of these losses on the frequency of reversal, the magnetic flux in the magnetic circuit of the motor and the geometric dimensions of the motor. Results. The mathematical model of calculation of starting parameters of the traction engine of the pulsating current of the traction drive of the electric locomotive of alternating current taking into account the equation of instantaneous value of losses in engine steel is developed. The dynamic characteristics of the traction motor with pulsating current are obtained. It allows to investigate starting parameters of the traction engine on the basis of the received mathematical model and to design elements of the traction drive of the electric locomotive according to the specification, to choose optimum design parameters. Originality. For the first time a comprehensive study of the pulsating current traction motor was carried out taking into account the nonlinear nature of the armature inductance, excitation winding inductance and nonlinear nature of the universal magnetic characteristic and taking into account the magnetic losses in the motor steel. Practical significance. The model of the traction motor of pulsating current taking into account losses in steel of the engine on the basis of the carried-out calculation is developed. Experimental studies have confirmed the adequacy of the model, which allows to apply the obtained model to develop a mathematical model of an AC electric locomotive to study the electrodynamic processes in it at different modes of operation of the electric locomotive. References 20, tables 2, figures 9.

Keywords: pulsating current traction motor, eddy currents, magnetic losses, magnetic circuit.

Запропоновано підхід до імітаційного моделювання тягових електродвигунів пульсуючого струму, заснований на врахуванні нелінійного характеру магнітної характеристики, індуктивностей якоря та обмотки збудження. Розроблено модель магнітних втрат у магнітопроводі якоря електродвигуна та досліджено їх вплив на характер електромагнітних процесів у електродвигуні. Показано, що отримані при цьому рімення узгоджуються з отриманими раніме результатами, але відкриваються додаткові можливості при дослідженні роботи двигуна в складі тягового електроприводу електровозу однофазно-постійного струму. Бібл. 20, табл. 2, рис. 9.

Ключові слова: тяговий двигун пульсуючого струму, вихрові струми, магнітні втрати, магнітне коло.

Introduction. Development and modeling of control algorithms for traction electric drives of single-phase DC electric locomotives with pulsating current traction motors require a reasonable choice of the model of traction electric motors. Simulation of work performed by pulsating current traction electric motors and systems used to control these motors should give a possibility to take into account a number of uncertainties. These uncertainties are related to the nonlinear nature of motor magnetization curve, occurrence of eddy currents in the magnetic circuit, and magnetic losses in the motor magnetic circuit caused by these currents. In addition, traction electric motor can operate with both full and attenuated excitation.

In this regard, one important circumstance can be noted. Taking into account a large number of works devoted to development of a model of pulsating current traction electric motor demanded models are those that take into account nonlinearity of magnetization characteristics and occurrence of eddy currents and magnetic losses in the motor magnetic circuit. This can be confirmed by works on approximation of magnetization characteristic $[1,2]$ and simulation of pulsating current traction electric motors of pulsating current taking into consideration influence of eddy currents on the nature of the magnetization curve [3]. Simulation models obtained in the result of applying these methods give an opportunity to determine with high accuracy such traction motor parameters as motor shaft speed at any load, currents flowing in traction motor circuits, electromotive force (EMF) generated by the motor, but taking into account all power losses in traction motor. This indicates that the subject of researches on development of a model of a pulsating current traction motor taking into account the nonlinear nature of the magnetization curve and the magnetic system as well as power losses in the traction motor is topical.

When modeling a direct current traction motor (DCM) of series excitation the main problem is to reproduce the dependence of magnetic flux on currents of field winding and armature currents; and this implies presence of load characteristics. In the work by [1] the authors propose to use universal magnetization curve for DCM of series excitation, and on the basis of universal magnetic characteristic to calculate universal expressions for the intrusive parameters of direct current traction electric machines and those of pulsating current traction motors. Since the universal magnetic characteristic is built for machines working under load, in order to reduce the error of approximation the author proposed to approximate the universal magnetic characteristic by means of two functions: magnetomotive force of the field winding and magnetomotive force of the armature reaction. For a particular rating of attenuation of excitation, it is possible to convert this expression into a function of one variable, such as armature current.

(C) S. Goolak, Ie. Riabov, V. Tkachenko, S. Sapronova, I. Rubanik 
With an obviously correct approach to modeling the dependence of the magnetic flux on field winding currents this approach is not very convenient for modeling. This is due to the need to change the model parameters for each excitation attenuation mode.

The solution of this problem is given in the work by [2] where it is proposed to calculate the weber-ampere characteristic at certain coefficients of field attenuation based on electromechanical and mechanical characteristics of DCM. Also this work proposes a model for determining the dependence of magnetic flux on field winding currents and the armature winding currents. The transfer function with unknown parameters in this model is considered as an adaptive model with coefficients adapted to the experimental data.

Since DCM used for traction purposes have certain peculiarities of design and magnetic system, the use of universal magnetic characteristics is not always correct. Motor magnetic circuits consist of electrical materials that have both high magnetic conductivity and high electrical conductivity. These materials are characterized by eddy currents that occur during change of magnetic flux. These processes significantly affect the change of magnetic flux in the motor steel and, accordingly, the nature of electromagnetic processes occurring in it. In works by $[1,2]$ the influence caused by eddy currents in the motor magnetic circuit on the change of magnetic flux is not taken into account. Solution of this problem can be found in the work by [3]. In this study the authors propose a mathematical model of the pulsating current traction motor taking into account influence of eddy currents on the nature of electrodynamic processes occurring in the electric motor.

Since DC motors of series excitation always operate in the loaded mode, electrodynamic processes in the electric motor should also be modeled taking into account the load. This can be confirmed by studies presented in works by [4-6]. The authors show relationship between the nature of load and mechanical characteristics of DCM.

In addition, the works by [7-9] represent the effect of load on motor magnetic characteristic, which, in turn determine electromagnetic characteristics of DCM. But the above works do not show the transition from mathematical models to their implementation in simulation models.

The study by [10] states that during electric locomotive operation movement parameters are constantly changing starting, traction mode, braking mode, braking mode, skidding, etc.). As the operating mode (rating) is changed the motor shaft speed also changes. Magnetic losses in the magnetic circuit of the traction motor depend on the motor shaft speed [11-13].

When calculating magnetic losses in magnetic circuit of pulsating current traction electric motor certain difficulties occur. These difficulties are associated with the choice of loss calculation method. Different loss calculation methods use different normalization coefficients or ratios at the same approach to loss determination in DCM. Moreover, in different methods, the value of similar coefficients may differ significantly from each other. This leads to discrepancies in the results of loss calculations in DCM when applying different methods [14-16].
The solution to this problem can be found in the study by [17] where the authors based on the analysis of existing methods have identified and proposed the most accurate approach to calculation and modeling of instant magnetic losses in steel of DC traction motor on the example of NB-418K6 motor.

Therefore, the aim of the article is to develop a mathematical model of a traction motor with pulsating current taking into account magnetic losses to study electrodynamic processes.

Simulation model of pulse current traction motor. Simulation of electrodynamics processes in a pulsating current traction motor was performed on the example of the NB-418K6 traction motor. Rating data of NB-418 K6 pulsating current traction motor is presented in Table 1.

Table 1

Rating data of NB-418 K6 pulsating current traction motor

\begin{tabular}{|l|c|c|c|}
\hline \multicolumn{1}{|c|}{ Parameter } & Designation & Units & Value \\
\hline Nominal voltage & $U_{d}$ & $\mathrm{~V}$ & 950 \\
\hline Nominal power in the continuous rating & $P$ & $\mathrm{~kW}$ & 740 \\
\hline Nominal current in continuous rating & $I_{a}$ & $\mathrm{~A}$ & 820 \\
\hline $\begin{array}{l}\text { Nominal speed of the motor } \\
\text { shaft in continuous rating }\end{array}$ & $n$ & $\mathrm{rpm}$ & 915 \\
\hline Nominal torque on the motor shaft & $T$ & $\mathrm{~N} \cdot \mathrm{m}$ & 7727 \\
\hline $\begin{array}{l}\text { Armature winding resistance } \\
\text { at } t=115^{\circ} \mathrm{C}\end{array}$ & $r_{a w}$ & $\Omega$ & 0.01612 \\
\hline $\begin{array}{l}\text { Resistance of additional poles } \\
\text { and field winding at } t=115^{\circ} \mathrm{C}\end{array}$ & $r_{a p+c w}$ & $\Omega$ & 0.01612 \\
\hline Resistance of main poles at $t=115^{\circ} \mathrm{C}$ & $r_{m p}$ & $\Omega$ & 0.01064 \\
\hline Field winding resistance at $t=115^{\circ} \mathrm{C}$ & $r_{f}$ & $\Omega$ & 0.001 \\
\hline Number of pole pairs & $p$ & - & 3 \\
\hline $\begin{array}{l}\text { Number of pairs of parallel } \\
\text { branches in armature winding }\end{array}$ & $a$ & - & 3 \\
\hline Number of armature winding conductors & $N$ & - & 696 \\
\hline Inertia moment of the motor rotor & $J$ & $\mathrm{~kg} \cdot \mathrm{m}^{2}$ & 73 \\
\hline Cross sectional area of the armature yoke & $S_{Y}$ & $\mathrm{~m}^{2}$ & 0.0810 \\
\hline Cross sectional area of the armature teeth & $S_{z}$ & $\mathrm{~m}^{2}$ & 0.0415 \\
\hline
\end{tabular}

Electric scheme of the DC traction motor is presented in Fig. 1.

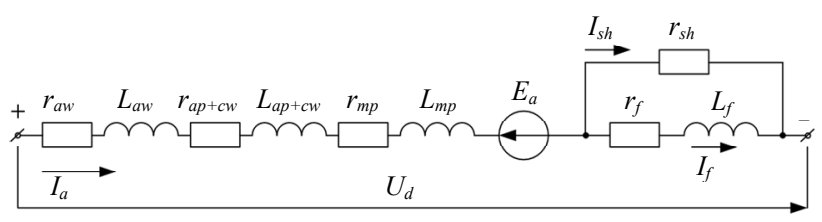

Fig. 1. Electric scheme of the pulsating current traction motor windings:

$r_{a w}, r_{a p+c w}, r_{m p}, r_{s h}, r_{f}$-active resistances of armature winding, additional poles and compensation winding, main poles, shunt,

field winding; $L_{a w}, L_{a p+c w}, L_{m p}, L_{f}$ - inductances of armature winding, additional poles and compensation winding, main poles, field winding; $U_{d}$-armature voltage; $E_{a}$ - armature EMF;

$I_{a}, I_{s h}, I_{f}$ - currents of armature, shunt and field winding

According to Kirchhoff's laws equations of the motor electrics for the circuit shown in Fig. 1 are as follows:

$$
\begin{gathered}
U_{d}=E_{a}+r_{a} \cdot I_{a}+L_{a} \cdot \frac{d I_{a}}{d t}+r_{s h} \cdot I_{s h} ; \\
r_{s h} \cdot I_{s h}=L_{f} \cdot \frac{d I_{f}}{d t}+r_{f} \cdot I_{f} ; \\
I_{a}=I_{s h}+I_{f},
\end{gathered}
$$


where $E_{a}$ is the armature electromotive force; $r_{a}, L_{a}$ are the active resistance and inductance of armature circuit respectively; $r_{f}, L_{f}$ are the active resistance and inductance of field winding respectively; $r_{s h}$ is the resistance of shunt resistor; $I_{a}$ is the armature current; $I_{f}$ is the field winding current; $r_{s h}$ is the resistance of shunt resistor; $U_{d}$ is the armature voltage.

For convenience of modeling electrical scheme of the pulsating current traction motor windings is shown in the following form (Fig. 2).

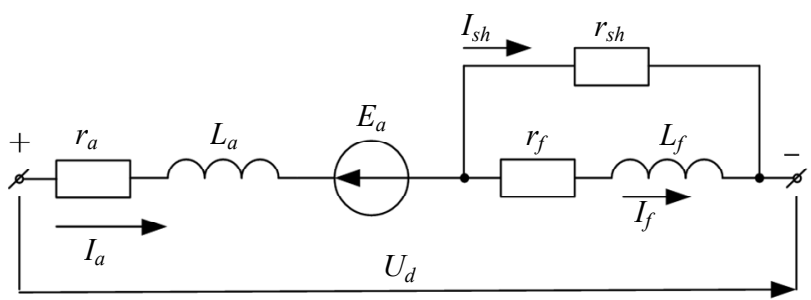

Fig. 2. Simplified electric scheme of the pulsating current traction motor windings: $r_{a}$ - active resistance of armature; $L_{a}$ - inductance of armature circuit

Armature resistance is defined as

$$
r_{a}=r_{a w}+r_{a p+c w},
$$

where $r_{a w}$ is the armature winding active resistance; $r_{a p+c w}$ is the active resistance of additional poles and compensation winding.

Armature inductance is defined as

$$
L_{a}=L_{a w}+L_{a p+c w},
$$

where $L_{a w}$ is the inductance of armature winding; $L_{a p+c w}$ is the inductance of additional poles and compensation winding.

Electromotive force $E_{a}$ is calculated as

$$
E_{a}=C_{E} \cdot \Phi \cdot \omega,
$$

where $C_{E}$ is the constructive constant coefficient for $\mathrm{EMF} ; \Phi$ is the total magnetic flux of the motor.

Constructive constant coefficient for EMF for shaft speed expressed in rpm is determined by the following expression

$$
C_{E}=\frac{N \cdot p}{2 \cdot \pi \cdot a},
$$

where $N$ is the number of armature winding conductors; $p$ is the number of pole pairs; $a$ is the number of pairs of parallel branches in armature winding.

Equation of motor mechanical equilibrium:

$$
M-M_{c}=J \cdot \frac{d \omega}{d t},
$$

where $M$ is the torque moment; $M_{c}$ is the load moment on the motor shaft; $J$ is the inertia moment of the motor rotor; $\omega$ is the angular motor shaft speed.

For modeling convenience expression (8) is represented as a derivative of the angular velocity over time:

$$
\frac{d \omega}{d t}=\frac{1}{J} \cdot\left(M-M_{c}\right)
$$

Torque moment is determined according to the following expression:

$$
M=C_{M} \cdot \Phi \cdot I_{a},
$$

where $C_{M}$ is the constructive constant coefficient for the moment.
Constructive constant coefficients for the EMF and for the moment are equal $\left(C_{E}=C_{M}\right)$.

In this research, the authors propose to implement the model of pulsating current traction motor on the basis of real magnetic characteristics of the motor.

Magnetic characteristics of NB-418 K6 traction motor is presented in Fig. 3 [17].

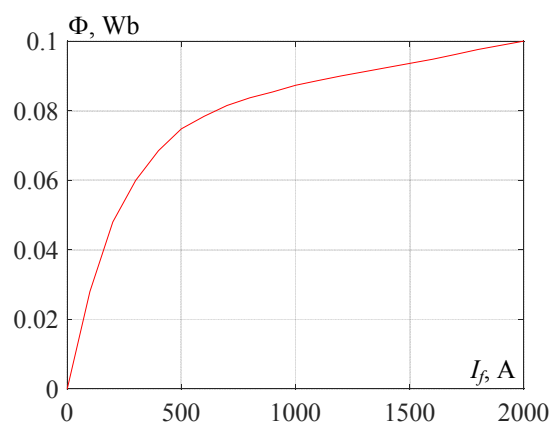

Fig. 3. Dependence of the magnetic flux $\Phi$ of the NB-418 K6 traction motor on the field current $I_{f}$

Consideration of magnetic losses in traction motor steel is performed according to the algorithm presented in equations $(11)-(20)$.

Specific power losses in electrical steel on eddy currents and hysteresis, taking into account the accumulation of magnetic energy at a given magnetic permeability $\mu_{r}=1$, as a function of time, respectively [17] can be presented by the following equations:

$$
\begin{aligned}
& p_{\text {loss }}(t)=\left(H_{c}+K_{\text {hys }} \cdot\left|B_{p} \cdot \sin \left(\omega_{r} \cdot t\right)\right|\right) . \\
& \cdot\left(B_{p} \cdot \omega_{r} \cdot \cos \left(\omega_{r} \cdot t\right)\right)+ \\
& +K_{\text {addy }} \cdot B_{p}^{2} \cdot \omega_{r}^{2} \cdot \cos ^{2}\left(\omega_{r} \cdot t\right),
\end{aligned}
$$

where $p_{\text {loss }}$ is the specific power losses, $\mathrm{W} / \mathrm{m}^{3} ; H_{c}$ is the coercive force; $V_{i s}$ is the induction amplitude of the charge; $\omega_{r}$ is the frequency of alternating magnetization; $t$ is the time; $K_{a d d y}$ is the coefficient taking into account specific losses on eddy currents; $K_{\text {hyst }}$ is the coefficient taking into account the specific losses on hysteresis.

Frequency of alternating magnetization can be found from the expression

$$
\omega_{r}=p \cdot \omega
$$

where $p$ is the number of pole pairs; $\omega$ is the rotation frequency of electric motor shaft.

In order to implement the model of magnetic losses in electrical steel, it is necessary to find the amplitudes of inductions in the nodes made of electrical steel - yoke and anchor teeth [17].

Magnetic induction in the armature yoke can be calculated by means of the following expression

$$
B_{a}=\frac{2 \cdot \Phi_{\alpha}}{S_{a}},
$$

where $S_{a}$ is the cross sectional area of the armature yoke [17]; $\Phi_{a}$ is the armature magnetic flux.

Magnetic induction in the armature teeth can be calculated by means of the following expression

$$
B_{z}=\frac{\Phi_{a}}{S_{z}},
$$

where $S_{z}$ is the cross sectional area of the armature teeth [17]. 
The armature magnetic flux is equal to the total magnetic flux of the traction motor.

The total magnetic loss is the sum of magnetic losses in the armature and armature teeth, i.e.

$$
p_{\text {loss } \Sigma}(t)=p_{\text {loss } Y}(t)+p_{\text {lossz }}(t),
$$

where $P_{\text {loss } Y}(t), P_{\text {lossz }}(t)$ are the magnetic losses in the armature core and armature teeth.

The given magnetic permeability of 2212 steel differs from 1 [17]. That is, for the transition from a generalized steel sheet with reduced magnetic permeability $\mu_{r}=1$, defined by means of equation (11), to a 2212 steel sheet with permeability $\mu_{r 1}$ equation (15) should be multiplied by $\mu_{r 1}$.

Coefficients $H_{c}, K_{\text {hyst }}$ and $K_{a d d y}$ in equation (11) were determined for specific power losses expressed in $\mathrm{W} / \mathrm{kg}$. For transition to losses expressed in watts, equation (11) should be multiplied by the mass of steel of the corresponding motor structural element. Mass of steel of the structural element is determined by the following expression

$$
m_{i}=\rho \cdot V_{i},
$$

where $V_{i}$ is the volume of the structural element; $\rho=7750 \mathrm{~kg} / \mathrm{m}^{3}$ is the specific weight of 2212 electrical steel.

Then the instantaneous values of losses in the yoke and anchor teeth, taking into account equation (11) can be expressed as follows:

$$
\begin{aligned}
& P_{\text {loss } Y}(t)=p_{\text {loss } Y}(t) \cdot \rho \cdot V_{Y}^{2} \cdot \mu_{r 1} \\
& P_{\text {lossz }}(t)=p_{\text {lossz }}(t) \cdot \rho \cdot V_{z}^{2} \cdot \mu_{r 1},
\end{aligned}
$$

where $V_{Y}, V_{z}$ are the volumes of armature yoke steel and steel of armature teeth respectively; $\mu_{r 1}=2400$ is the relative magnetic permeability of 2212 steel at frequency of $50 \mathrm{~Hz}$ and inductance $B=1.82 \mathrm{~T}$ [17].

Magnetic losses in the motor steel of the model are taken into account as follows. Relationship between active power and engine shaft speed is defined by the following expression:

$$
P_{\text {loss }}=\omega \cdot M_{\text {closs }},
$$

where $M_{\text {closs }}$ is the static moment caused by magnetic losses in the motor steel.

Hence the static moment caused by the magnetic losses in the motor steel is s follows

$$
M_{\text {closs }}=\frac{P_{\text {loss }}}{\omega} \text {. }
$$

The work by [18] shows that both armature circuit inductance and inductance of field winding have a nonlinear dependence on armature current and field current respectively. In this regard, the model of the electrical part of the traction motor in the MATLAB software environment was implemented in the Special Power System section of the Simulink library. This gave an opportunity to use real values of motor winding resistances, and the nonlinear dependences of the armature circuit inductance and field winding inductance on the corresponding currents was substituted with units of controlled current sources. Control signals for current sources simulating armature circuit inductance and field winding inductance were presented as the following dependences

$$
\begin{aligned}
& I_{a}=f\left(\psi_{a}\right), \\
& I_{f}=f\left(\psi_{f}\right),
\end{aligned}
$$

where $\psi_{a}$ is the flux linkage of armature; $\psi_{f}$ is the flux linkage of field winding.

Flux linkages $\psi_{a}$ and $\psi_{f}$ were obtained based on expressions (1) i (2) respectively.

With this end in view, based on the results for dependences of the armature circuit inductance and field winding inductance on the corresponding currents presented in the work [18], dependence of the armature current on the armature circuit flux linkage (Fig. 4) and dependence of field winding current from field current (Fig. 5) were calculated and constructed.

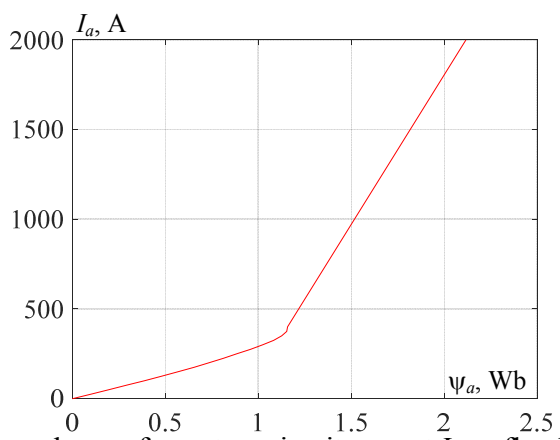

Fig. 4. Dependence of armature circuit current $I_{a}$ on flux linkage $\psi_{a}$

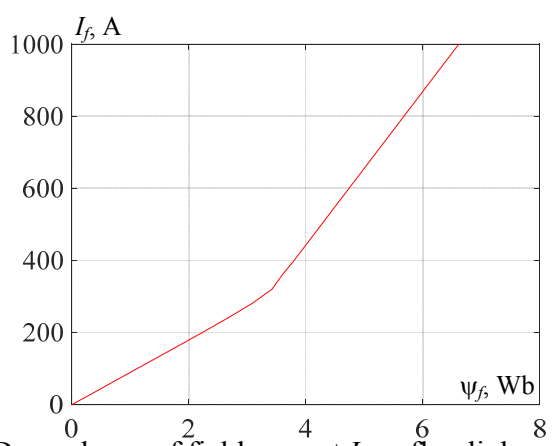

Fig. 5. Dependence of field current $I_{f}$ on flux linkage of field winding $\psi_{f}$

All other structural elements of the traction motor model were presented in form of structural diagrams.

Simulation model performed on the example of the NB-418 K6 traction electric motor used on electric locomotives of alternating current VL-80T, VL-80K (Fig. 6).

Implementation of the traction motor electrical part in the MATLab software environment is shown in Fig. 6 in form of the «Engine currents determination unit». Calculation of magnetic flux performed by approximation of the magnetic characteristic (Fig. 3) based on the arctangent function. In Fig. 6 implementation of Magnetic Characteristic is presented in form of the «Magnetic flux detection unit».

Electric motor mechanical part in Fig. 6 is represented in form of the "Unit for calculating the mechanical parameters of the engine» that implements equations (9), (10). Calculation of instantaneous values of magnetic losses in electric motor steel that implements equations $(11)-(20)$ is presented in the simulation model in form of the «Unit for calculating the static moment caused by magnetic losses» (Fig. 6). 

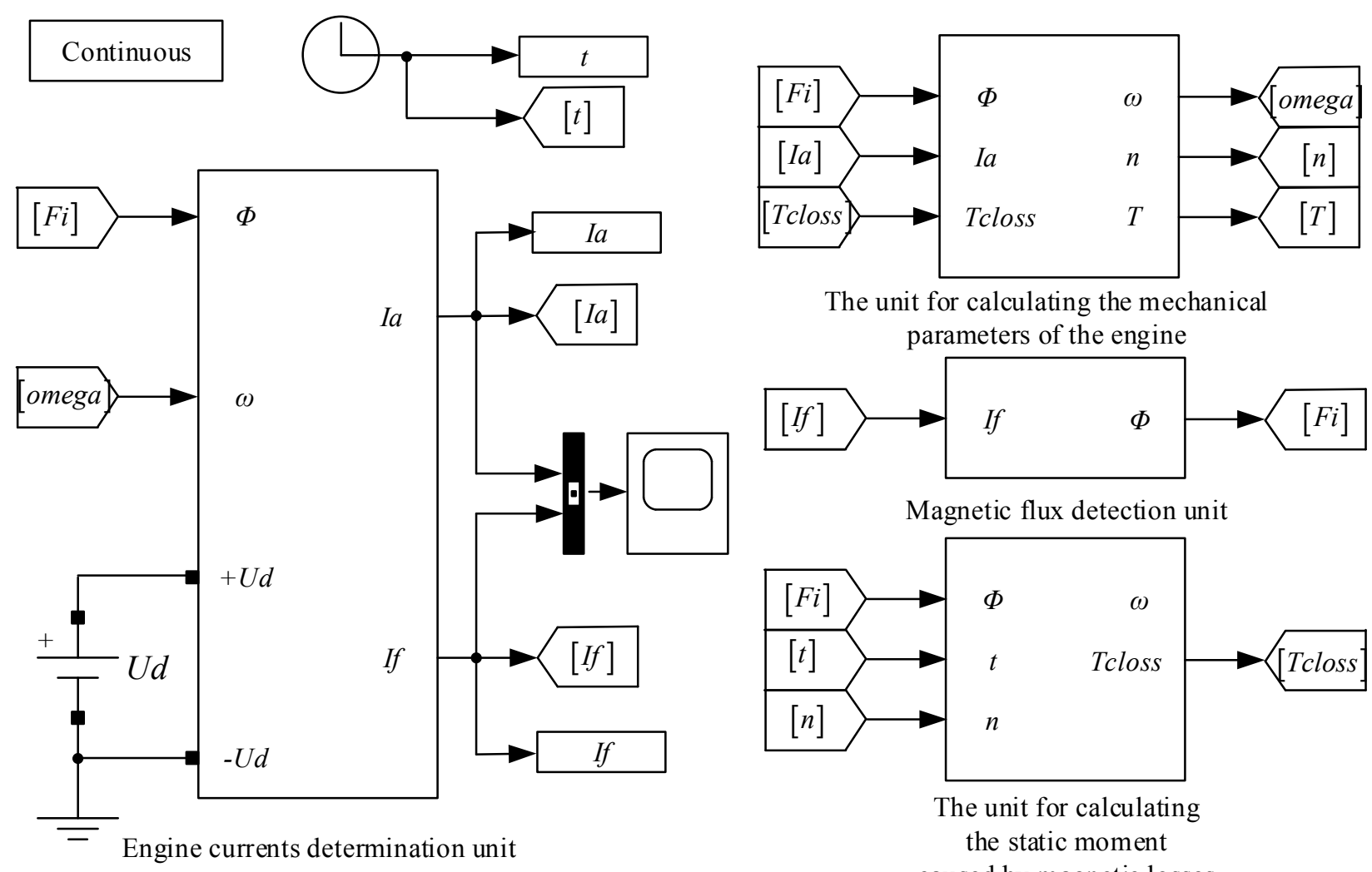

The unit for calculating the mechanical parameters of the engine
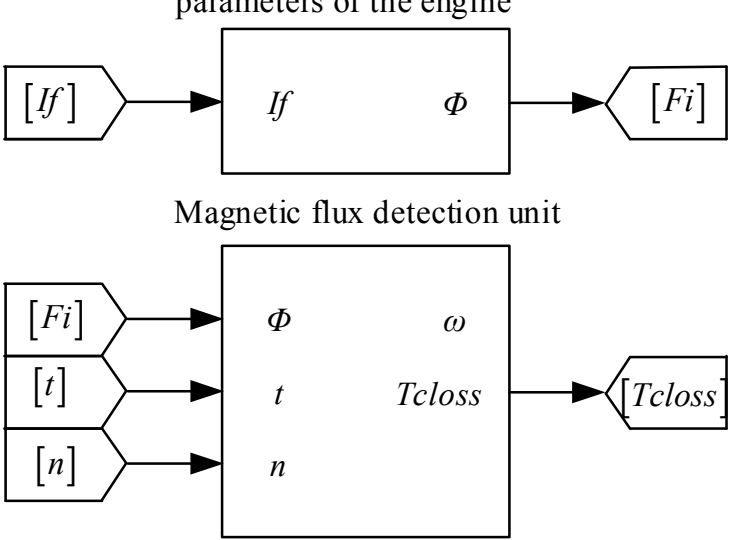

The unit for calculating

the static moment caused by magnetic losses
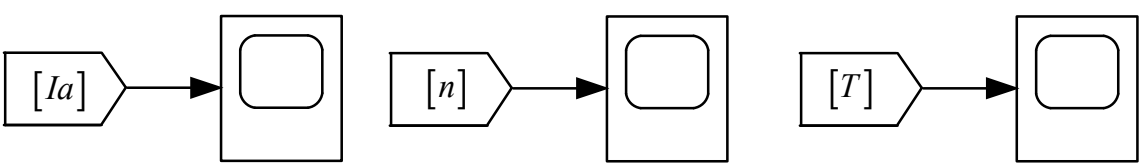

Fig. 6. Simulation model of a traction electric motor implemented in the MATLAB software environment

Simulation results. In order to determine starting characteristics of pulsating current traction electric motor a constant voltage $U_{d}$ of $950 \mathrm{~V}$ corresponding to the nominal voltage value for NB-418 K6 traction motor. In the «Unit for calculating the mechanical parameters of the engine» a static moment $T_{c}$ of $7727 \mathrm{~N} \cdot \mathrm{m}$ was created; and in the «Engine currents determination unit» shunt resistance $r_{s h}$ was accepted as $0.24 \Omega$ and these values also correspond to the nominal mode of electric motor operation.

On the simulation model (Fig. 6) obtained are time diagrams of armature current (Fig. 7), torque moment on the electric motor shaft (Fig. 8) and motor shaft speed (Fig. 9).

For the steady-state rating a value of excitation flux $\Phi$ was equal to $0.0819 \mathrm{~Wb}$.

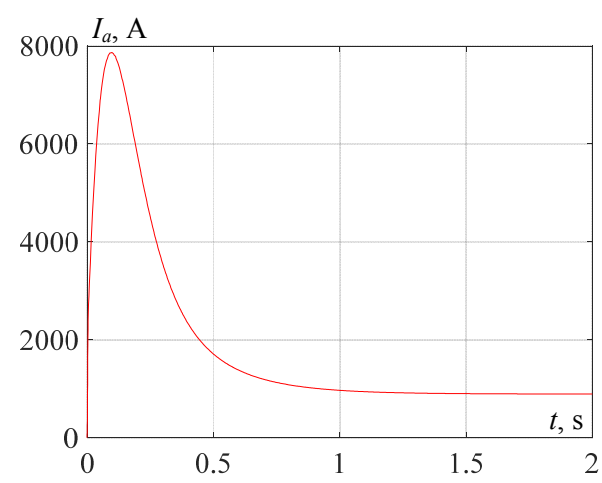

Fig. 7. Time diagrams of armature current $I_{a}$

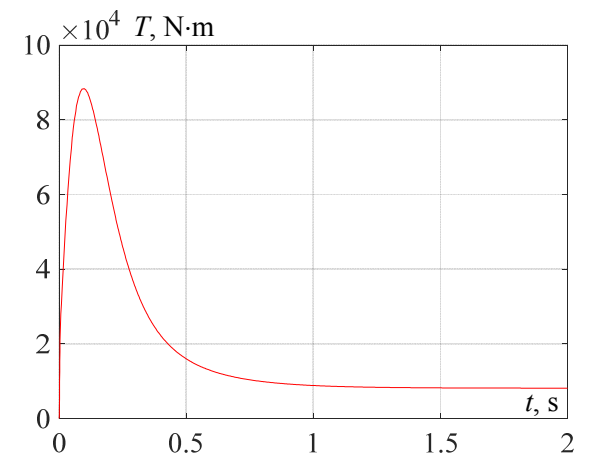

Fig. 8. Time diagram of torque moment $T$ on the motor shaft

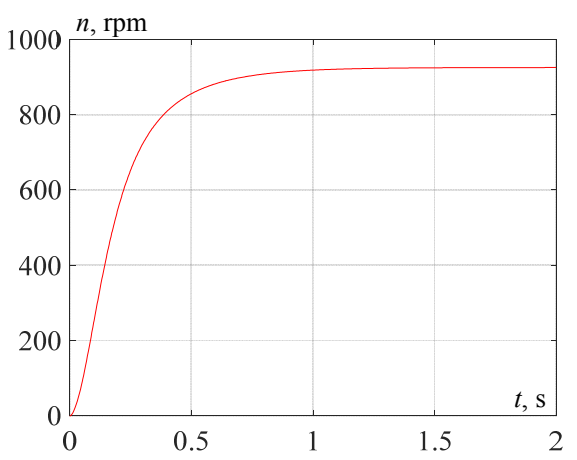

Fig. 9. Time diagram of motor shaft speed $n$

Values of armature circuit current, the torque moment on the motor shaft, motor shaft speed and the 
magnetic flux for the steady-state rating obtained during the simulation were used to calculate errors in determining these values.

Error in determination of armature circuit current

$$
\begin{aligned}
& \delta_{I_{a}}=\left|\frac{I_{\text {anom }}-I_{\text {amod }}}{I_{\text {anom }}}\right| \cdot 100 \%= \\
& =\left|\frac{820-881}{820}\right| \cdot 100 \%=6,93 \%,
\end{aligned}
$$

where $I_{\text {anom }}=820 \mathrm{~A}$ is the armature nominal current (see Table 1); $I_{\text {amod }}=881 \mathrm{~A}$ is the armature current obtained in the result of modeling for the steady-state rating.

Flux determination error

$$
\begin{aligned}
& \delta_{\Phi}=\left|\frac{\Phi_{\text {nom }}-\Phi_{\text {mod }}}{\Phi_{\text {nom }}}\right| \cdot 100 \%= \\
& =\left|\frac{0,08-0,0819}{0,08}\right| \cdot 100 \%=2,375 \%,
\end{aligned}
$$

where $\Phi_{\text {anom }}=0.08 \mathrm{~Wb}$ is the nominal magnetic flux (see Table 1); $\Phi_{\text {amod }}=0.0819 \mathrm{~Wb}$ is the magnetic flux obtained in the result of modeling for the steady-state rating.

Error in determination of torque moment on the motor shaft:

$$
\begin{aligned}
& \delta_{T}=\left|\frac{T_{\text {nom }}-T_{\text {mod }}}{T_{\text {nom }}}\right| \cdot 100 \%= \\
& =\left|\frac{7727-7990}{7727}\right| \cdot 100 \%=3,4 \%,
\end{aligned}
$$

where $T_{\text {anom }}=7727 \mathrm{~N} \cdot \mathrm{m}$ is the nominal torque moment on the motor shaft (see Table 1); $T_{\text {amod }}=7990 \mathrm{~N} \cdot \mathrm{m}$ is the torque moment on the motor shaft obtained in the result of modeling for the steady-state rating.

Error in determination of torque moment on the motor shaft:

$$
\begin{aligned}
& \delta_{n}=\left|\frac{n_{\text {nom }}-n_{\text {mod }}}{n_{\text {nom }}}\right| \cdot 100 \%= \\
& =\left|\frac{915-951,6}{915}\right| \cdot 100 \%=4 \%,
\end{aligned}
$$

\begin{tabular}{|c|c|c|c|c|c|c|c|c|c|c|c|c|}
\hline \multirow{3}{*}{ Rating } & \multicolumn{12}{|c|}{ Controlled parameter } \\
\hline & \multicolumn{3}{|c|}{ Armature current $I_{a}, \mathrm{~A}$} & \multicolumn{3}{|c|}{ Static moment $T, \mathrm{~N} \cdot \mathrm{m}$} & \multicolumn{3}{|c|}{ Motor shaft speed $n, \mathrm{rpm}$} & \multicolumn{3}{|c|}{ Flux $\Phi, \mathrm{Wb}$} \\
\hline & $I_{a}$ & $I_{\text {amod }}$ & $\delta_{I a}, \%$ & $T$ & $T_{\text {mod }}$ & $\delta_{T}, \%$ & $n$ & $n_{\text {mod }}$ & $\delta_{n}, \%$ & $\Phi$ & $\Phi_{\text {mod }}$ & $\delta_{\Phi}, \%$ \\
\hline$U_{d}=950 \mathrm{~V}$ & \multirow{3}{*}{820} & \multirow{3}{*}{881} & \multirow{3}{*}{6.93} & \multirow{3}{*}{7727} & \multirow{3}{*}{7990} & \multirow{3}{*}{3.4} & \multirow{3}{*}{915} & \multirow{3}{*}{951.6} & \multirow{3}{*}{4.0} & \multirow{3}{*}{0,08} & \multirow{3}{*}{0,0819} & \multirow{3}{*}{2,375} \\
\hline Excitation $96 \%$ & & & & & & & & & & & & \\
\hline$T_{c}=7727 \mathrm{~N} \cdot \mathrm{m}$ & & & & & & & & & & & & \\
\hline$U_{d}=1080 \mathrm{~V}$ & \multirow{3}{*}{840} & \multirow{3}{*}{885.3} & \multirow{3}{*}{5.39} & \multirow{3}{*}{7727} & \multirow{3}{*}{8030} & \multirow{3}{*}{3.9} & \multirow{3}{*}{1050} & \multirow{3}{*}{1088} & \multirow{3}{*}{3.5} & \multirow{3}{*}{0,082} & \multirow{3}{*}{0,0839} & \multirow{3}{*}{2,317} \\
\hline Excitation $96 \%$ & & & & & & & & & & & & \\
\hline$T_{c}=7727 \mathrm{~N} \cdot \mathrm{m}$ & & & & & & & & & & & & \\
\hline$U_{d}=950 \mathrm{~V}$ & \multirow{3}{*}{1155} & \multirow{3}{*}{1212} & \multirow{3}{*}{4.93} & \multirow{3}{*}{7727} & \multirow{3}{*}{8174} & & & & & & & \\
\hline Excitation $43 \%$ & & & & & & 5.78 & 1055 & 1091 & 3.41 & 0,11 & 0,1127 & 2,45 \\
\hline$T_{c}=7727 \mathrm{~N} \cdot \mathrm{m}$ & & & & & & & & & & & & \\
\hline$U_{d}=950 \mathrm{~V}$ & & & & & & & & & & & & \\
\hline Excitation $96 \%$ & 665 & 691.8 & 4.03 & 5597 & 5859 & 4.68 & 965 & 996.2 & 3.23 & 0,065 & 0,0664 & 2,154 \\
\hline$T_{c}=5597 \mathrm{~N} \cdot \mathrm{m}$ & & & & & & & & & & & & \\
\hline
\end{tabular}

where $n_{\text {anom }}=915 \mathrm{rpm}$ is the rated motor shaft speed (Table 1$) ; n_{\text {amod }}=951.6 \mathrm{rpm}$ is the motor shaft speed obtained in the result of modeling for the steady-state rating.

Results of modeling and calculation of errors in determination of controlled motor parameters are listed in Table 2.

Results of calculation of errors in determination of controlled parameters during modeling

The results shown in Table 2 indicate a high reliability of measuring controlled parameters. Thus, the armature current measurement error for all measurement modes did not exceed $7 \%$; torque measurement error was up to $6 \%$; the error of measuring the motor shaft speed was not more than $4 \%$ and the error of measuring the magnetic flux did not exceed $3 \%$. This indicates a high reliability of the modeling results and increases the accuracy of calculations of energy-intensive modes of rolling stock [19, 20].

\section{Conclusions.}

The use of the unit for determining the magnetic losses in the motor armature of the motor made it possible to clarify values of the controlled parameters during modeling. Comparison of the controlled parameters in the steady-state rating with the motor passport data showed a high degree of reliability of the simulation results. Thus, the armature current measurement error for all measurement modes did not exceed $7 \%$; torque measurement error was up to $6 \%$; the error of measuring the motor shaft speed was not more than $4 \%$, the error of measuring the magnetic flux did not exceed $3 \%$. Further refinement of the mathematical model is related to taking into account all types of losses in the motor components when it is powered from a pulsating voltage source.

The proposed approach to modeling of a pulsating current traction electric motor will give an opportunity to apply this model for development of a mathematical model of the traction electric drive of an electric locomotive aimed at studying electrodynamic processes occurring in the electric drive.

The presence of the unit for determining magnetic losses in the motor steel will give an opportunity to reliably assess spectral composition of the traction current and voltage in the secondary winding of the traction transformer at various modes of electric locomotive operation. This, in turn, will give an opportunity to evaluate operation of reactive power compensators taking into account various modes of electric locomotive operation. 
Funding. This work was supported by the Ministry of Education and Science of Ukraine in the project DR No. 0120U101912: Increasing the energy efficiency of rolling stock based on resource-saving technologies and smart energy systems.

Conflict of interest. The authors declare that they have no conflicts of interest.

\section{REFERENCES}

1. Nayak B., Sahu S., Choudhury T.R. Parameter estimation of DC motor using adaptive transfer function based on NelderMead optimization. Indonesian Journal of Electrical Engineering and Computer Science, 2018, vol. 9, no 3, pp. 696702. doi: https://doi.org/10.11591/ijeecs.v9.i3.pp696-702.

2. Drubetskyi A.Y. Approximation of universal magnetic characteristic for modelling electric traction machines. Science and Transport Progress. Bulletin of Dnipropetrovsk National University of Railway Transport, 2017, no. 1(67), pp. 106-116. doi: https://doi.org/10.15802/stp2017/94031.

3. Kulinich Yu.M., Shukharev S.A., Drogolov D.Yu. Simulation of the pulsating current traction motor. VNIIZHT Scientific Journal, 2019, vol. 78, no. 5, pp. 313-319. (Rus). doi: https://doi.org/10.21780/2223-9731-2019-78-5-319.

4. Shepovalova O.V., Belenov A.T. Investigation of DC Motors Mechanical Characteristics with Powered by Comparable Capacity PV Array. Energy Procedia, 2017, vol. 119, pp. 990994. doi: https://doi.org/10.1016/j.egypro.2017.07.132.

5. Evseev, V. Y., Savos'kin, A. N. A Mathematical Model of a Collector Traction Motor with Separate Consideration of Eddy Currents of the Main and Additional Poles. Russian Electrical Engineering, 2020, vol. 91, no 9, pp. 557-563. doi: https://doi.org/10.3103/s1068371220090047.

6. Litovchenko V.V., Nazarov D.V. Sharov V.A. Simulation Model of a Direct-Current Electric Locomotive with Commutator Traction Motors. Russian Electrical Engineering, 2020, vol. 91, no. 1, pp. 69-76. doi: https://doi.org/10.3103/s1068371220010071.

7. Spiryagin M., Wolfs P., Cole C., Spiryagin V., Sun Y.Q., McSweeney T. Design and Simulation of Heavy Haul Locomotives and Train. New York, Taylor \& Francis Group, 2016. 477 p. doi: https://doi.org/10.1201/9781315369792.

8. Castaneda C.E., Loukianov A.G., Sanchez E.N., CastilloToledo B. Discrete-Time Neural Sliding-Mode Block Control for a DC Motor With Controlled Flux. IEEE Transactions on Industrial Electronics, 2012, vol. 59, no. 2, pp. 1194-1207. doi: https://doi.org/10.1109/TIE.2011.2161246.

9. Kharchenko V., Kostenko I., Liubarskyi B., Shaida V., Kuravskyi M., Petrenko O. Simulating the traction electric drive operation of a trolleybus equipped with mixed excitation motors and a DC-DC converter. Eastern-European Journal of Enterprise Technologies, 2020, vol. 3, no. 9 (105), pp. 46-54. doi: https://doi.org/10.15587/1729-4061.2020.205288.

10. Goolak S., Tkachenko V., Bureika G., Vaičiūnas G. Method of spectral analysis of traction current of AC electric locomotives. Transport, 2020, vol. 35, no 6, pp. 658-668. doi: https://doi.org/10.3846/transport.2020.14242.

11. Liu R., Li L. Calculation Method of Magnetic Material Losses Under DC Bias Using Statistical Loss Theory and Energetic Hysteresis Model. IEEE Transactions on Magnetics, 2019, vol. 55, no 10 , pp. 1-4. doi: https://doi.org/10.1109/TMAG.2019.2921357.

12. Zhang H., Mueller M. Electromagnetic properties of curved HTS trapped field stacks under high-frequency cross fields for high-speed rotating machines. Superconductor Science and Technology, 2021, vol. 34, no 4, pp. 045018. doi: https://doi.org/10.1088/1361-6668/abe4b6.

13. Kwon H., Park H. Numerical Investigation of Optimal Air Flowrate for Cooling $600 \mathrm{~W}$ Brushless Direct-Current Motor. Journal of Thermal Science and Engineering Applications, 2021, vol. 13, no 4, pp. 041008. doi: https://doi.org/10.1115/1.4048755.

14. Rens J., Vandenbossche L., Dorez O. Iron Loss Modelling of Electrical Traction Motors for Improved Prediction of Higher Harmonic Losses. World Electric Vehicle Journal, 2020, vol. 11, no 1, p. 24. doi: https://doi.org/10.3390/wevj11010024.

15. Zhao J., Quan X., Jing M., Lin M., Li N. Design, Analysis and Model Predictive Control of an Axial Field Switched-Flux Permanent Magnet Machine for Electric Vehicle/Hybrid Electric Vehicle Applications. Energies, 2018, vol. 11, no. 7, pp. 1859. doi: https://doi.org/10.3390/en11071859.

16. Cheng G., Guo X., Wen Y., Wang Q., Li G., Zhou R. Electromagnetic Modeling and Analysis of 3-DOF Permanent Magnet Spherical Motor Using Magnetic Equivalent Circuit Method. 2018 21st International Conference on Electrical Machines and Systems (ICEMS), 2018, pp. 2643-2648. doi: https://doi.org/10.23919/ICEMS.2018.8548998.

17. Goolak S., Sapronova S., Tkachenko V., Riabov I., Batrak Y. Improvement of the model of power losses in the pulsed current traction motor in an electric locomotive. EasternEuropean Journal of Enterprise Technologies, 2020, vol. 6, no. 5 (108), pp. 38-46. doi: https://doi.org/10.15587/17294061.2020.218542.

18. Goolak S., Tkachenko V., Sapronova S., Spivak O., Riabov I., Ostroverkh O. Determination of inductances for pulsating current traction motor. Technology audit and production reserves, 2021, vol. 2, no. 1(58), pp. 40-43. doi: https://doi.org/10.15587/2706-5448.2021.229217.

19. Petrenko A.N., Liubarskiy B.G., Pliugin V.E. Determination of railway rolling stock optimal movement modes. Electrical Engineering \& Electromechanics, 2017, no. 6, pp. 27-31. doi: https://doi.org/10.20998/2074-272X.2017.6.04.

20. Buriakovskyi S.G., Maslii A.S., Panchenko V.V., Pomazan D.P., Denis I.V. The research of the operation modes of the diesel locomotive CHME3 on the imitation model. Electrical Engineering \& Electromechanics, 2018, no. 2, pp. 59-62. doi: https://doi.org/10.20998/2074-272X.2018.2.10.

Received 11.10.2021 Accepted 13.11.2021 Published 03.12.2021

S. Goolak ${ }^{1}, P h D$,

Ie. Riabov ${ }^{2}$, PhD, Associate Professor,

V. Tkachenko ${ }^{1}$, Doctor of Technical Science, Professor,

S. Sapronova ${ }^{1}$, Doctor of Technical Science, Professor,

I. Rubanik ${ }^{3}$, Chief Designer,

${ }^{1}$ State University of Infrastructure and Technologies,

9, Kyrylivska Str., Kyiv, 04071, Ukraine,

e-mail: sgoolak@gmail.com (Corresponding Author).

${ }^{2}$ National Technical University «Kharkiv Polytechnic Institute»,

2, Kyrpychova Str., Kharkiv, 61002, Ukraine.

${ }^{3}$ JSC «Riga Electric Machine Building Works»,

53, Ganibu Dambis Str., Riga, LV-1005, Latvia.

How to cite this article:

Goolak S., Riabov Ie., Tkachenko V., Sapronova S., Rubanik I. Model of pulsating current traction motor taking into consideration magnetic losses in steel. Electrical Engineering \& Electromechanics, 2021, no. 6, pp. 11-17. doi: https://doi.org/10.20998/2074$\underline{272 X .2021 .6 .02 .}$ 